\title{
Relating self and other in Chinese and western thought
}

Dr Astrid H. M. Nordin, Department of Politics, Philosophy and Religion, County South, Lancaster University, Lancaster LA1 4YL, United Kingdom. a.nordin@lancaster.ac.uk

Dr Graham M. Smith, School of Politics and International Studies, Social Sciences Building, University of Leeds, Leeds LS2 9JT, United Kingdom.ipigms@leeds.ac.uk

\section{Bios:}

Astrid H. M. Nordin holds a PhD from the University of Manchester. She is Director of Lancaster University China Centre, Senior Lecturer in the Department of Politics, Philosophy and Religion at Lancaster University, Senior Fellow of the Institute of Social Futures, and Research Fellow at the Swedish Institute of International Affairs. She recently published articles in International Affairs, Review of International Studies, Millennium, Alternatives and China Information. She is the author of the monograph China's International Relations and Harmonious World (Routledge, 2016).

Graham M. Smith is Lecturer in Political Theory at the University of Leeds, with a $\mathrm{PhD}$ from Lancaster University. He has a special interest in friendship and has published in Critical Review of International Social and Political Philosophy, Political Studies Review, and International Politics. He is also the author of Friendship and the Political (Imprint Academic, 2011) and is currently writing a monograph entitled Friendship and Political Theory (for Edinburgh University Press).

\begin{abstract}
Recent debates in International Relations seek to decolonise the discipline by focusing on relationality between self and other. This article examines the possibilities for preserving a particular type of otherness: 'radical otherness' or 'alterity'. Such otherness can provide a bulwark against domination and colonialism: there is always something truly other which cannot be assimilated. However, two problems arise. First, if otherness is truly inaccessible, how can self relate to it? Does otherness undermine relationality? Second, can we talk about otherness without making it the same? Is the very naming of otherness a new form of domination? This article draws out and explores the possibilities for radical otherness in Sinophone and Anglophone relational theorising. It addresses the difficulties presented by the need for a sense of radical otherness on the one hand, and the seeming impossibility of either detecting it, or relating to it, on the other. By constructing a typology of four accounts of otherness, it finds that the identification and preservation of radical otherness poses significant problems for relationality. Radical otherness makes relationality between self and other impossible, but without radical otherness there is a danger of domination and assimilation. This is common to both Sinophone and Anglophone endeavours.
\end{abstract}




\section{Introduction}

What is the relation between self and other? Indeed, can there be a relation at all? This article shows new resources available to answer these questions, and highlights the complexities in trying to do so. In order to do so, this article focuses on recent debates surrounding relational theorising in International Relations (IR). Although there are different forms of relational thinking, it can be said that this approach takes as its starting point the idea that things are effects of relations, and that nothing can simply 'be' without being in relation. In charting the literature and debates around this idea, this article shows that not only are these debates internally complex but also have complex realtions to each other. At least three vectors can be considered to be in play. First, these debates can be characterised as drawing from different theoretical backdrops leading to a range of ontological and ethical commitments. Second, these debates can be chacterised as exploring the notions of self and other, East and West, 'us' and 'them', whilst simultaneously challenging such constructions. Finally, debates over relationality now take place in a context of increasing calls for 'worlding' (Tickner and Blaney 2012), 'decolonizing' the discipline (Gruffyd Jones 2006) 'beyond the West' and for a 'global IR' (Acharya 2014). As such there have been attempts to move away from what might be traditionally thought of as a 'Western' model of IR.

It is against this background that this article makes its intervention. Specifically, this article focuses on the possibilities for preserving a particular type of otherness in these debates: 'radical otherness' or 'alterity'. This form of otherness is significant, because identifying and preserving it can provide a bulwark against domination and colonialism. There is always something that is truly other which cannot be incorporated, understood, synthesised, or assimilated. In order to achieve this goal this article constructs a typology for foregrounding 'radical otherness' in the established IR debates. By highlighting 'radical otherness' in this way this tool necessarily intervenes to organise the material in the debates. It brings some things into the foreground (such a otherness and relationality), whilst leaving other concerns in the background. Although our endeavour is a theoretical one and remains at the level of abstraction, this intervention is significant as it lays the foundation for a clearer examination of examples and case studies by other scholars.

Given that both the focus on 'radical otherness' and the method used to focus on it carry limitations and risks the next section discusses these. Next, after we have discussed the limitations of the typology, the remainder of this article goes on to trace 'radical otherness' in selected Anglophone and Sinophone relational theorising. It should be noted from the start that we do not attempt to encompass all the possible strands of this literature which would also include work originating from India (such as that of Nandy), North Africa (such as that of Memmi) and the Caribbean (such as that of Fanon). Instead our current focus and limitations of space mean that we will only examine dominant strands of scholarship originating from what many of these literatures call 'the West'.

Our typology identifies and names four specific models of self/other relationality: (1) role relationality, where there are different roles, but no theorised relation to otherness; (2) 
hierarchical relationality, where the other awaits incorporation into the self; (3) dialectic relationality, where the other is in the self and the self is in the other; and (4) aporetic relationality, where the other is anterior to the self. Each type has its limits for thinking relationality and otherness, and raises questions and challenges to the others. The presentation of these models also draws attention to the differing construction and priorities that are present in their ethical understanding of the relation between self and other. What the typology highlights is the complex web of interconnections between the models of self and other when viewed through the lens of 'radical otherness'. As will be seen, although the typology brings some coherence to this complex picture it also begins to indicate how that coherence is less stable than might be thought. In creating this picture, the typology also shows the instability of the very categories on which it relies for its construction: self-other, East-West, and us-them.

\section{Limitations}

Before we can investigate 'radical otherness' through our typology it is important to note two features of our endeavour. The first concerns the notion of typology itself. The typology is not just 'there' but - as indicated above - is a part of an intervention. That intervention does not simply occur in a vacuum. It is an active naming and ordering of material to serve a purpose. The second concerns what 'radical otherness' or 'alterity' is and why it is important. Moreover, it also concerns the limitations of the concept itself. In using this concept we acknowledge that it is a foundational assumption. It could be that readers challenge the construction or the existence of such alterity. This article does not intend to defend alterity or to mount a discussion of its epistemological and ontological status per se. Instead, the employment of alterity in this article is justified by its usefulness. In other words, the use of alterity allows us to bring a certain kind of order to our subject matter, and to highlight some similarities and contrasts. As such, we are mindful that such interventions must always be accompanied by some violence. Thus, this theoretical endeavour is an attempt to both see and understand. However, we do not merely record what is there. The exercise is also a demonstration of the appearance and disappearance of this radical other for relationality. As we discuss radical otherness (and its relation to the self) we rely on what it excludes - the other senses of otherness and self. Thus, when outlining and ordering the literature below, we are conscious that things could be arranged differently, depending on what sense of 'self and other' is brought into relief. The appearance of such otherness looks very different in different strands of relational thinking, as does its relation to the imagined self.

The first limitation revolves around the selection and ordering of our material. In this article we discuss literature which often self-identifies (and identifies its 'other') in binary opposites such as East and West, Anglophone and Sinophone, Colonial and de-colonial. In addition, many of the authors that we cite draw their resources from what they identify as a particular tradition of thinking. There are obvious strategic reasons for Chinese scholars to identify their work with 'Chinese tradition' when they are operating in an academic context that is dominated by Anglophone scholarship and that arguably marginalises China as the 'Other country' and its scholars as informants (cf. Chow 1991, Kristensen and Nielsen 2013). We would argue in 
addition that these authors do not simply report 'what is there' but, by speaking and acting as if distinct traditions existed, they in part constitute them. This article is no different insofar as we also 'constitute' what we discuss. However, we nevertheless follow the self-identification of our authors in order to elucidate features of the debates that they have engaged in, and ultimately to unravel or destabilise some of the categories and assumptions that they make. This is especially true of the essentialisation of East and West, which in many ways stands as a proxy for the essentialisation of self and other. Our focus on alterity is, in part, an attempt to find a device to effect this work of destabilisation.

This leads to the second limitation: the use of 'others', 'self' and 'alterity'. Two problems arise. These problems are theoretical in nature: (1) If this form of otherness is truly inaccessible, how can the self relate to it? (2) Does talking of this kind of otherness threaten the very domination it seeks to avoid? This article explores the possibilities for this form of otherness in both Anglophone and Sinophone relational theorising in IR. It does so by comparing and contrasting scholarship that draws on what its authors tend to call Chinese and Western traditions, identifying points of convergence and divergence as well as discussing the multiple ways in which otherness is used in this literature. The purpose of this article is to highlight the difficulties that the need for a sense of radical otherness presents on the one hand, and the seeming impossibility of either detecting it or relating to it, on the other.

However, herein lays the third limitation and difficulty with our endeavour. Both 'self' and 'other' are Western (indeed, Anglophone) terms, interwoven with a number of related terms, including us and them, sameness and difference, friend and enemy, and so on. Chinese language has a similar array of terms that are used to discuss the type of concern that is our focus here, where ziwo (自我) and tazhe (他者) are probably the closest terms in use. Our use here of the Anglophone 'self' and 'other' limits what can be seen and understood. Moreover, even within the confines of the English language, self and other have a complex lexical relation. Whilst 'self' and 'other' are often contrasted, their meanings are not stable. For our present purposes it is useful to identify and compare three uses of 'self': (1) as a subject in the sense of an individual or person differentiated from other subjects; (2) as the same which is contrasted to the other as difference; and (3) as knowable and accessible, contrasted to the other as unknowable and inaccessible. Although this article focuses on the third meaning, inevitably its focus is not unqualified. Self and other indicate a complex of related meanings, and these meanings come to influence and support each other. The other senses of the word 'haunt' the preferred usage - indeed, they help to structure it.

There are then, three senses of self and other and a word or two needs to be said about how they are related. First, 'self' is sometimes used as a synonym for 'the subject'. In much Western tradition (particularly in liberal and enlightenment thought), this has been predominantly (although not exclusively) realised in terms of a bounded individual, separate from others, possessing special access to their own body and mind. Here 'self' means a subject in relation to other subjects. The self indicates personhood or individuality and although that person lives in a social world of other persons their self is taken to be distinct and complete in its own right. 
This is reflected in a strand of European thought which takes the self to be an a priori philosophical construct. In this strand of thought the self is assumed to be complete and exists before any relations to others, or any experience of the world. Such selves form a starting point for political theorising in which the self has intrinsic qualities and rights before their engagement with others in society. The second sense maps sameness and difference onto self and other. Here the idea is that the 'self-same' is that which shares the qualities of the self (for example, the friend is another self not only because they are another subject, but also because they are like their friend, cf. Smith, 2011). Otherness is understood in terms of difference.

These two senses of self and other can be compared to the third sense that we are especially interested in here: what we term 'radical otherness' or alterity. This third sense of otherness constructs self as that which we can know and have access to, and otherness as the unknowable and inaccessible. As a result, this sense of otherness indicates a limit to assimilation, categorization, and understanding. The other is constructed as a hard limit for the self, a limit that cannot be broached and assimilated. Although pinning the other down in definition necessarily does some injustice to this otherness of the other, we may borrow from Levinas to note that: 'The alterity of the absolutely other is not an original quiddity of some sort.... The Other is not a particular case, a species of alterity, but the original exception to the order' (Levinas 1998: 12-13). However, it is the very inaccessibility of radical otherness which suggests the impossibility of relationality.

This third sense of otherness also returns us to decolonisation. Decolonizing efforts aim to challenge the tendency in Eurocentric tradition to devalue, deny, or disallow other ontologies and epistemic worlds (see e.g. Ling, 2014). This Eurocentric tradition tends to allow for otherness as difference, but it finds it harder to accommodate otherness as alterity. This is not universally so. In twentieth century continental theorising the notion of 'alterity' has been entertained by figures such as Levinas and Derrida. This is another instance of the transience of the categories of East and West which are often used to speak as if there were two opposed and unified traditions. Nevertheless, the dominant trend of Eurocentric theorising and policy has been to see others as somehow like the same - albeit inferior or less civilised (see for example Inayatullah and Blaney, 2004). In contrast to such Eurocentric tradition, the 'other' that is of concern to decolonizing debates is therefore not simply the understandable or fathomable difference that permeates IR, but the more profound alterity that extends beyond that realm of what is knowable to this specific self.

\section{Typology: Four Forms of Relationality}

\section{1) Role relationality: different roles, but no relation to otherness}

'Role relationality' theorises what are arguably relations between the self and another self, rather than the self and an other in the sense outline above. Such a model is found in variants of network theory, some pragmatist work, the bulk of 'mainstream constructivism', and role 
theoretical work based on both Chinese and Western traditions. These accounts correspond to what Nexon and Jackson refer to as primarily 'positional' analysis in their contribution to this special issue. Such accounts have made significant and valuable contributions to relational thinking. However, their contribution to thinking about relationality and otherness as alterity is limited because they are confined to considering knowable difference in a shared world of knowledge.

Wendt's work Social Theory of International Politics provides an illustrative example (Wendt 1999). For Wendt, constructivism is not a theory of IR, but a way of approaching ontology that is applied to a subject matter or field of enquiry (Wendt 1999, 7). This ontology gives us a classic understanding of self and other as co-constitutive. As Wendt writes:

in initially forming shared ideas about Self and Other through a learning process, and then in subsequently reinforcing those ideas casually through repeated interaction, Ego and Alter are at each stage jointly defining who each of them is (Wendt 1999, 335).

While this language might suggest that the ideas of self and other are doing significant work, there is no room in Wendt's theorization for the self to relate to otherness. The truly other is absent from theorisation. Wendt clearly uses the language of self and other. However his construction and use of 'the other' is developed in such a way as to empty the other of their otherness and make them necessarily relate to, and assimilate into, the world of the self or same. In other words, whilst Wendt talks about the self and other, his use of 'other' is such that it can only appear when incorporated into the conceptual framework of the same. This is a very different use of the term to the 'radical otherness' sketched above, which cannot be incorporated into a conceptual framework of the self and same but remains a limit to it.

This absence of otherness comes to the fore in Wendt's insistence that the roles states can take in relation to one another (enmity, rivalry or friendship) are only possible within a shared culture, as he sees 'roles as properties of macro-structures, as collective representations' (Wendt 1999, 257, see also 249, 251 for further comments). Indeed, the very first page of Social Theory of International Politics makes very clear that in his view 'the structures of human association are determined primarily by shared ideas' (Wendt 1999, 1). Wendt's cultures of anarchy do not depend on difference or alterity between the actors whose relations he wishes to theorise, but on what understandings they share. If this is the case then there is no room for radical otherness. Otherness is a limit to Wendt's framework of shared cultures, but it is a limit that he does not sufficiently theorise. What is at stake here is that Wendt can only theorise otherness when it is linked to, and a function of, sameness. Otherness appears as a placeholder in the script of the same, it is not presented as a limit or rupture to that script.

In this respect it is worth considering Wendt's theorisation of the 'first encounter' between Cortés and Moctezuma (Wendt 1999, 158; for previous discussions of this encounter see: Inayatullah and Blaney 1996, 71-74; Pasic 1996, 87-90; Ling 2014, 30; Nordin and Smith 2018, 381-2; cf. Zehfuss 2001, 326-7). On Wendt's reading, when Cortés and Moctezuma 
meet, they are truly other or alien to one another, and neither fits into the other's script or existing world view. As Wendt explains the matter, '[it is an empirical question whether actors share any ideas, and sometimes they do not. When the Spaniards encountered the Aztecs in 1519, their interaction was highly structured by their beliefs about each other, beliefs that were rooted in pre-Encounter experiences and thus not shared' (Wendt 1999, 158). Wendt uses this encounter to illustrate his claim that culture needs to be shared, which means that these actors cannot be said to take on any of his three 'roles' until the other has been brought into the culture or epistemic realm of the self. Their initial relation - a relation between genuinely or radically self and other - defines what cannot be theorized within Wendt's constructivist view of 'relations.' His shared culture cannot exist between self and other in this sense, which limits the relations he can theorise to that between a self and what we may better understand as another self. As he puts it, '[b]y taking a particular role identity Ego is at the same time "casting" Alter in a corresponding counter-role that makes Ego's identity meaningful' (Wendt 1999, 329). Therefore, Wendtian identity is central and possible precisely because in others the self sees not alterity and difference, but an Alter Ego (Nordin and Smith 2018, 382).

Wendt's notion of roles is clearly derivative of a particular Western experience (Wendt 1999, 258-259). Elsewhere, scholars have suggested that Chinese tradition offers a more genuinely relational manner of understanding roles. Notably, Taiwanese scholars Shih Chih-yu and Huang Chiung-chiu offer what they term the 'balance of relationship' as an alternative framework to the realist 'balance of power' (Huang and Shih 2014; Huang 2015; Shih 2016). Huang suggests that the balance of relationship reflects a systemic force which 'drives states to seek long-term reciprocal relationship regardless of differences in values, regime type, and power status,' and which 'becomes the main theme of foreign policy especially in states whose domestic culture (political as well as social) provides strong support for the relation-oriented strategic thinking' as is said to be the case in, for example, Taiwan, Singapore, Myanmar, and China (Huang 2015, 193, 194; Shih 2016). On this view, such states act with self-restraint to 'acquire stable relationships or to rectify a wrong relationship' (Huang 2015, 193).

Huang focuses her analysis on bilateral relationships, and Shih elsewhere suggests that such a bilateral or dyadic focus is particular to Chinese IR. To Shih, this focus is rooted in 'the reciprocal bilateralism of Confucianism,' in contrast with the multilateral relationality of 'Western IR' (Shih 2016, 682). Like many other scholars who draw on Chinese tradition, Shih is interested in emphasizing how this approach differs from what are understood as 'Western' approaches. According to Shih, 'indigenous' Chinese theorists (including Qin, discussed below and contributing with Nordin to this special issue), claim that actors seek to construct a collective 'greater self' and secure their own role therein, to be favourably treated as part of the in-group, and avoid discrimination directed against the out-group. Shih contrasts his 'Chinese' version of relationality with Wendtian constructivism. Yet he seems to share Wendt's ontological position that actors are co-constitutive only insofar as they share an established relationship and understanding of their reciprocal obligations in that relationship. As in Wendt's analysis, 'roles taken by one constitute one's self-identity,' and 'nations are defined by their identities vis-a-vis their multiple dyadic selves, not by what they are 
themselves' (Shih 2016, 685, 687).

Importantly, 'relationality is a process of reproducing hypothetically established relationships, not one of re/constructing fresh relations as in Jackson and Nexon's formulation' (Shih 2016, 685). Just as Wendt cannot theorise the first encounter between Cortés and Moctezuma within

his framework, so too can Huang and Shih's version of the balance of relationship only account for relations between those who already share culture. Again, there seems to be little room for radical otherness in the sense we set out in the introduction to this article. Shih turns away from relational ontology as change (which he associates with Wendt and Hegelian dialectics), in favour of an allegedly Chinese view which requires 'no ontological adaptation,' and where 'each Chinese self acquires the skill to adapt, thus ensuring their continuous belonging to the same and known greater self' (Shih 2016, 687). Actors (states) may take on different roles at different points in time, but the 'selves' that interact in this balance of relationship and the roles they can take are prescribed. Moreover, 'differences pose no barrier to one's inclusion in the dyadic self, as long as the roles required by the relationship are faithfully enacted' (Shih 2016). What Shih elsewhere discusses in terms of a specifically Asian self is therefore understood by him literally as 'the self that has no other' (Shih 2010).

Wendt's constructivism, and Huang and Shih's 'balance of relationship', have both made significant and welcome contributions to understanding the way actors change their roles, identities, intentions, and behaviours through interaction. However, the ontological category of the self that defines these actors remains fixed. The self in these theories either has no other, or is unable to 'relate' to otherness. As such, these types of analyses may deploy the language of the 'relationality' of 'self' and 'other,' but remain firmly defined by what other literatures on relationality have termed an 'ontology of things,' as opposed to a 'relational ontology' (Jackson and Nexon 1999; Nordin and Smith 2018). Nevertheless, these approaches help raise and address important questions, questions which have both empirical and normative dimensions: What roles, identities, intentions, and behaviours can we observe as emerging from discursive and material processes? How are various 'selves' or 'identities' produced by specific distinctions? In what ways do such 'selves' relate and create shared understandings of their respective roles?

\section{2) Hierarchical relationality: the other awaits incorporation into the self}

The constructivist scholarship discussed above is also representative of a significant portion of work emerging from the contemporary Chinese academe. Simultaneously, other Sinophone scholars have focused on theorising world relations based on what philosopher Zhao Tingyang, in line with Shih, calls a 'Chinese ontology, the ontology of relations, instead of the western ontology of things' (Zhao 2006b, 33). Zhao has also put forward one of the most influential proposals for how to theorise through relations developing the Ancient Chinese concept of Tianxia, which he variously translates as 'the world,' 'empire', or 'All-under-heaven' (Zhao 2005; 2006b). 
Whereas Wendt is content to accept and theorise the international state-system, Zhao is criticial of its Western-centrism. He argues that instead of viewing the world from one country's point of view, his Tianxia can offer 'a view from nowhere' or a view 'from the world' (Zhao 2005; 2006b). Such a holistic approach to world order should be led by a normative commitment to a harmony of difference, rather than sameness or unity:

given that the world is in a state of existing difference, and difference can take the form of conflict, there are at least two kinds of schemes of resolution (jiejue fang'an 解决方案), one is “unity” (tong 同), that is the unification (tongyi 统一) of value systems and ideologies. This scheme is unworkable, because "unity cannot endure" (tongzebuji 同则不继). The other kind is “harmony" (he 和), that is establishing maximized mutual benefit of mutual coordination in the midst of difference (Zhao 2006a, 1).

Furthermore, Zhao criticises the state system because '[s]uch projects have essential difficulties in reaching the real integrality of the world,' and what is needed is '"inclusion of all' in All-under-Heaven,' and 'wholeness or totality rather than the between-ness' (Zhao 2006b, 33, 37, 39). In a similar way to Wendt or Huang and Shih, Zhao therefore begins by insisting on a relational ontology, but ends up emphasising the homogeneity of his allinclusive space. As such, he argues that 'all political levels ... should be essentially homogenous or homological so as to create a harmonious system', that '[ $t$ ]he world's effective political order must progress from All-under-Heaven, to state, to families, so as to ensure universal consistency and transitivity in political life, or the uniformity of society', and again that 'any inconsistency or contradiction in the system will be a disaster' (Zhao 2006b, 33, emphasis in original). This will be achieved by transforming the 'many' into 'the one' (Zhao 2005, 13, also pointed out by Callahan 2008, 257). As in the analyses by Wendt or Huang and Shih, what appears to get lost in Zhao's insistence on uniformity is sustained relationality to genuine otherness.

Zhao's form of relationality differs most clearly from Wendt's, Huang's and Shih's in that Zhao's Tianxia system is not simply explanatory, but explicitly utopian. It seeks to explain the world, and create a better world. Moreover, in order for the existing world with all its heterogeneity to pass into such homogeneity, some people must change (Nordin 2012, 237; 2016a, 50). Zhao explains that:

one of the principles of Chinese political philosophy is said "to turn the enemy into a friend", and it would lose its meaning if it were not to remove conflicts and pacify social problems - in a word, to "transform" (hua 化) the bad into the good (Zhao 2006b, 34). 
Zhao maintains that transformation will come through 'voluntariness'; people will simply see how good the Tianxia elites are, and will want to become like them without proselytism (Zhao 2006b, 36). ${ }^{1}$

This understanding of hierarchy as a normative good stands out as a clear departure from many non-Chinese accounts of relationality which imply (but rarely explicitly defend) some form of epistemic equality or democracy as a benefit of relational thinking. In contrast, Zhao's project is led by (Chinese) elites. As he frankly claims, 'most people do not really know what is best for them, but ... the elite do, so the elite ought genuinely to decide for the people' (Zhao 2006b, 32). Zhao suggests that the benefit of such a 'civilization/barbarism' interaction in Chinese history was an objective discussion of the long term advantages and disadvantages of different cultures (Zhao 2005). However, many critics have agreed with William A. Callahan that Zhao's vision 'sounds like a hierarchy of cultures analogous to modern racism and the PRC's current concern with the "population quality" of its ethnic minorities and of the peoples of the world' (Callahan 2008, 755; Barabantseva 2009; Nordin 2012, 237-238; 2016a, 50-51). The adoption of hierarchy as a good resonanates with a highly patriarcal Ancient Chinese tradition, that was often elaborated as a guide to self-cultivation for the elite 'gentlemen' (junzi 君子). Such gentlemen were to govern Tianxia. Notably, questions of gender have been absent from its contemporary theorisation. Parallells could also be drawn to other teleological 'progress' stories that operate on the possibility of turning other into self. In such stories, others are not really different, but just behind. Eventually, they will become like us. ${ }^{2}$

Critics may be sceptical of Zhao's account which actively calls for the eradication of those who do not fit into the elite's preferred order by turning the other into self. According to Zhao, and despite his apparent rejection of 'unity' (tong 同), it is only after such conversion into 'homogeneity' that we can reach enough epistemic and ontological coherence to speak of a 'world' (shijie 世界) at all (Zhao 2005, 13; Zhao 2006b). He is explicit that such a world has 'no outside' (wuwai 无外). This normative insistence on one homogeneous world conflicts with decolonial literatures. Such literatures insist on the ontological multiplicity of 'worlds' in coexistence as a prerequisite for relational thinking and for giving parity to non-Eurocentric knowledge systems such as the Chinese tradition of thinking in terms of Tianxia (Rojas, 2016).

Scholars who support democracy on the baisis that it promotes equality might be tempted to simply dismiss Zhao's account due to its justifiaction of inequality. However, a careful reading of Zhao reveals that he not only justifies inequality, but that he also works with a certain notion of equality. This notion is different to those supported by many other IR scholars. We suggest that the questions it raises are pressing. Is it not also true that democratic traditions often construct what they consider to be acceptable inequalities, especially in the form of outsiders who are excluded from a given democratic system? What, then, is the place of hierarchy in

\footnotetext{
${ }^{1}$ For discussion of the way this hierarchy in Zhao plays out specifically through 'friendship' as one of the five Confucian relationships, see Nordin and Smith (2018).

2 See Nordin (2016a) and Nordin (2016b) for discussion of this move in broader comparisons of European democracy and Chinese harmony.
} 
these different traditions of relational thinking? If the commitment to relational ontology is not in itself uniquely Chinese (as Zhao suggests, but this special issue disputes), is the Chinese approach distinctive simply because of its overtly normative commitment to hierarchy? If this is so, what does that mean for its potential contribution to a post-Western or decolonial project? How might it respond to feminist critiques of the family as a model of good hierarchical governance? Can Tianxia be further theorised as conceivable within a pluriverse, or how can it otherwise provide a better relational alternative to pluriversal thinking? If Tianxia is indeed a revived defence of Empire and of the hierarchy of cultures, what makes it more palatable than Western iterations? Conversely, what is so wrong with hierarchy? Scholars committed to equality or democracy as a normative feature of relationality are directly challenged by Chinese scholars like Zhao to explicitly defend their position in the context of decolonial struggles in and beyond the academe.

\section{3) Dialectic relationality: the other is in the self and the self is in the other}

Another increasingly influential approach in Sinophone thought is the 'golden mean' or zhongyong (中庸) dialectic that is illustrated by the Daoist yin-yang (阴阳) symbol. This symbol consists of a circle formed of two halves, one black, one white. There is a black dot in the white, and a white dot in the black.

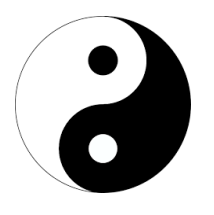

Figure 1: Yin-yang (Wikimedia commons, 2012).

Qin Yaqing has been important in advocating this approach as a Chinese way of thinking about relationality, as embodied in the concept guanxi (关系) (Qin 2009, 9; 2016, 39; 2018; and his contribution with Nordin to this special issue). His account of relationality has become a key reference point for many who write about relationality in Chinese IR theorising, including Huang and Shih as discussed above. Like Zhao and Shih, Qin associates relationality with China and 'Confucian communities of practice', contrasting this to 'rationality' which is said to represent the background knowledge of Western societies (Nordin and Qin in this issue).

Qin suggests that Chinese yin-yang thinking escapes the dichotomising binaries of Western traditions of thought. According to Qin, Western thought tends to understand A and non-A as irreconcilable because they have essentially different properties, even if they are taken to interrelate in a Hegelian-style dialectic. Qin advocates a 'Chinese dialectic' where A can be non-A or include non-A. The process of relationships transform the behaviour and the essential properties of actors involved, so that A can transform non-A or be transformed into non-A. Thus, yin-yang relationality, 'denies the dichotomously structured concept of "thesis vs. anti- 
thesis" or "us vs. them." (Qin 2016, 40). Elsewhere, David L. Hall and Roger T. Ames also explain such a relationality in terms of non-binary contrast:

Yin and yang are not, as is so often claimed, dualistic principles of light and dark... where light and dark exclude each other, logically entail each other, and in their complementarity constitute a totality. Rather yin and yang are, first and foremost, a vocabulary of qualitative contrasts which are applicable to specific situations, and which enable us to make specific distinctions (Hall and Ames 1995, 261).

Yin and yang characterize particular relationships that enables one to unravel patterns of relatedness and to interpret specific circumstances. It is only through a process of generalization that, for example, gender traits constructed as feminine and masculine have been construed as predominantly yin and yang respectively, and the contrast essentialized (Hall and Ames 1995, 261). That is not to say that Chinese tradition has not been patriarchal - it certainly has (Wolf 1994). However, it indicates that the conceptual framework itself has less in common with theories that reify or seek to affirm such binaries. The yin and yang framework is instead more akin to those postcolonial, poststructuralist, feminist and queer theoretical approaches that focus on deconstructing essentialist binaries and demonstrating their contingency.

Such a postcolonial feminist understanding of yin-yang relationality is at the root of L. H. M. Ling's 'worldism' and Daoist dialectic (Ling 2014). Ling critiques what she calls 'Westphalia World', the common understanding or hegemonic vision of IR that includes 'mainstream approaches' characterised by an ontology of things. Ling shows how this view and its ontology 'perpetrates a profound violence' by denying its reliance on those it excludes, along with their knowledges and ways of knowing, what she calls 'Multiple Worlds'. These worlds are indeed multiple, consisting of 'the fundamental contributions made to world politics by others, by the subaltern, their knowledges and ways of knowing' (editor's preface to Ling 2014, xv). Ling also reacts against Wendt's claim that first encounters like those between Cortés and Moctezuma led to an accretion of culture at the systemic level, leaving the enemy, the rival and the friend as the only roles available to others, locking out any other considerations of relations among worlds (Ling 2014, 30). Such an ontology of things creates a "postcolonial anxiety" which festers in Multiple Worlds; this aggravates a "colonial anxiety" in Westphalia World" (Ling 2014,3), leading to a nihilistic logic where the lives of others are forfeited to save one's own.

Ling offers a Daoist dialectic as an alternative to this violent and anxious worldview. In such a Daoist dialectic the 'complementarities (yin) prevail despite the contradictions (yang) between and within the polarities. Nothing remains static or the same' (Ling 2014, 15). This worldview strives to re-centre marginalised contributions to world politics, conceptualising their ontological parity with Westphalia world. It is thus a response to the negative spiral of violence and anxiety in the relation between Westphalia World and Multiple Worlds:

A dao of world politics propels us from this dilemma. In recognizing the ontological parity of things, a post-Westphalian IR experiences the constant potential of creative transformations due to the mutual interactions that transpire, especially between 
opposites. Multiplicity and difference manifest, enacted by local agents and their transformations of knowledge (Ling 2014, 3).

In contrast to Wendt's account of relations which falls back on an ontology of things, this worldview emphasizes the complexity of a self which includes elements of the other. The language of yin and yang does not in itself guarantee that any analysis of concrete terms or encounters follows through on this aspiration to recognise the other in the self and vice versa. Instead, the suggestion here is that the language and tradition from which it stems never operated through thinking in terms of binary exclusions in the first place. Thus it can provide a resource for those who endeavour to make space for alterity, hybridity, and between-ness in IR theorising. The point, it should be clear, is not to replace Westphalia World with Multiple Worlds, or for the ontology of things to be superseded by relational ontologies. Rather, the Daoist dialectic urges us to move closer towards balance and engagement. In Ling's terms, '[f]ortified with Daoist dialectics, worldism re-visibilizes Multiple Worlds in relation to one another as well as to Westphalia World' (Ling 2014, 18). Equally, it makes multiple relational ontologies visible again, both in relation to one another and in relation to the ontology of things (Nordin and Smith 2018, 389). The area of intersection between different ontologies forms a dialogical space. However, unlike the Socratic dialogue, Daoist dialectics do not presuppose that there is a stable and discoverable truth independent of human perspectives (Ling 2014, 66). The point here is not to adjudicate between these ontologies, but to identify the contrast between them. This contrast is important because it can produce different political consequences. It is this politics of how self and same respond to otherness and difference which is at stake here.

Ling's insistence on this contrapuntuality between West and Rest, Self and Other, 'to jointly produce the complicities that endure despite and sometimes because of the mutual conflicts that tear them apart' adds an important emphasis to Qin's account (Ling 2014, 45). Qin is clearly aware that the relational ontology he advocates is not uniquely Chinese, having both ancient and contemporary parallels in Europe and elsewhere. Ling's efforts to articulate her 'Multiple Worlds' without falling back on dichotomisations of 'the West' and 'China' helps to underscore that the 'Chinese view' that Qin describes need not be exoticized as a geo-culturally specific example. On the contrary, it might even be that contemporary IR theories which have assumed an ontology of things and marginalised friendship relations should be considered a highly specific exception to a more general global and historical trend (Nordin and Smith 2018, 389; Smith 2011; Roshchin 2018).

Contemporary elaborations of a Daoist dialectic have thus begun to reformulate a relational ontology that conceives of self and other as distinct but connected. This articulation of relationality resonates with a postcolonial or decolonial agenda, as well as with feminist and poststructuralist efforts at deconstructing identities. In Ling's articulation there appears to be a clear concern with relating multiple worlds that are incommensurable. The recognition that there is other in the self suggests that even Wendtian 'shared culture' and Shih's 'self that has no other' are replete with otherness and fragmentation. The other is always already there; we can and do relate to otherness, both within and beyond the self. This logic points away from 
facile East/West dichotomisation and from the claim that relationality is simply Chinese and rationality is simply Western. The Daoist dialectic tells a more complicated story that acknowledges intermingling of self and other, potentially enabling more harmonious politics (Hagström and Nordin 2017). Yet questions remain about the normative role of hierarchy and equality in this dialectic. Could there be identities outside the yin-yang dialectic, or do we need to allow it to assume the role of a 'master concept' that risks falling back into the kind of totality that is criticized in Zhao's theorisation of Tianxia? If the Daoist dialectic enables parity or equality in the relations between worlds, is this compatible with dominance and deference in yin-yang relationality? Qin elaborates what he terms relational power as something an actor possesses by being well connected, but there seems to be more to be said here about conceptualising power and hierarchy in the Daoist dialectic.

\section{4) Aporetic relationality: the other is anterior to the self}

The final conceptualisation questions the very attempt to relate to the other as other. It ties together the third form of relationality (the other in the self) with the first (where the self has no relation to otherness). The seeming impossibility of relating to the other has been emphasised by readings of a Judeo-Christian divine by thinkers such as Kierkegaard, Levinas, and Derrida, which generated some debate in scholarship on the philosophy of religion, and particularly discussions of ineffability and meaning of life. One could also draw parallels here to psychoanalytic traditions and thinkers like Lacan, and their emphasis on constitution by lack - though some would question the applicability of psychoanalysis outside a particular European experience. More recently, Dillon has argued for a poststructuralist commitment to the 'anteriority of radical relationality' (Dillon 2000). By this he means that 'nothing is without being in relation, and that everything is - in the way that it is - in terms and in virtue of relationality' (Dillon 2000, 4). Most importantly, however, this 'anteriority of radical relationality' is conceptualised in terms of 'relationality with the radically non-relational' (Dillon 2000, 4). This radically non-relational is the other, 'the utterly intractable, that which resists being drawn into and subsumed by relation albeit it transits all relationality as a disruptive movement that continuously prevents the full realization or final closure of relationality, and thus the misfire that continuously precipitates new life and new meaning' (Dillon 2000, 5). The other, as the intractable, therefore defines the limit of relationality. How can it then be possible to be in radical relationality with this radically non-relational other? Even naming it seems to domesticate it and deny its alterity. Yet, Dillon insists, we always already are. That, he points out, is why Derrida refers to it as an 'aporia' (Dillon 2000; Derrida 1993). An aporia is a kind of impasse. It is a moment of undecidability or paradox which destabilises or undermines the very terms and context that establishes it. The aporia that Derrida and Dillon identify therefore marks the persistence of the radically non-relational in the relational, and it will always confound any notion of final order - which also means there will always be more ordering yet to come. 
This point resonates significantly with Buddhist, Daoist, and by consequence Confucian accounts. As Hall and Ames have argued, Ancient Chinese thinking does not presuppose a single-ordered world (Hall and Ames 1995, xviii). The opening chapter of the Daodejing, characterises the Dao ('the way' or 'the real') as follows:

The way that can be spoken of

Is not the constant way (Laozi 1996, I:1).

This is repeated in the Daodejing which restates that 'The way conceals itself in being nameless' (Laozi 1996, XXXII:72, XLI:92). Naming and knowing can grapple to some extent with aspects of the real, but it is totally inadequate to the purpose of truly understanding the real. Ultimately, the Dao is unknowable, and the truth is ineffable (Lau 1996, xviii). Yet the Dao is anterior to all, as 'The way begets one; one begets two; two begets three; three begets the myriad creatures' (Laozi 1996, XLII:93; IV:11). Although some interpret these 'myriad creatures' as an expression of Dao as an essence, we suggest that there can be at least one reading made where the Dao is an anterior non-originary origin that does not produce one single-ordered world (which again, we believe, resonates with Derrida).

In this way, Dillon's poststructuralist 'anteriority of radical relationality' and Laozi's Dao are significantly different to the commitments of Shih, Zhao, Qin, or complexity theorists. These thinkers draw from relationality a desire to understand the 'implicate orderliness' of the anteriority of radical relationality (Bohm 1980). In contrast, Dillon and Laozi emphasise disruption, disorder and the impossibility of conceiving of a 'shared culture' where knowable relations can be pinned down in prescribed roles. Ultimately, relationality escapes and exceeds all attempts to share and know, and there is always a surplus or an excess to the meaning we perceive. The insistence that, however impossibly and aporetically, we retain this anteriority of the other, or of radical relationality, seems to be a key point made by poststructuralist analyses such as Dillon's and our reading here of the Dao. Future discussions about relationality need to take this into account and question how this is done and how we situate the unknowable within our academic endeavours.

\section{Conclusion}

This article opened by asking a question about the relationship between self and other. It was asked how self relates to other, and what otherness might mean. This question was motivated by recent scholarship in IR that challenges a Eurocentric construction of otherness as mere difference. Such a construction leads to the assimilation and dominance of otherness, and the devaluation and dismissal of epistemologies, ontologies, and world views that cannot be incorporated into this purview. In this way, that approach lays the foundations for, and reproduces, a colonial logic and practice. The article attempted to trace the possibility of challenging this logic by examining how otherness has been constructed in a number of recent writings which focus on the relationality of self and other. In order to do this, it focused on one (promising) sense of otherness: radical otherness or alterity. It was hoped that such an otherness would provide a limit to the colonial enterprise. In constructing a typology of four different 
accounts of otherness, it was found that the identification and preservation of radical otherness posed significant problems for relationality. It would seem that radical otherness makes relationality between self and other impossible, but without radical otherness there is a very real danger of domination and assimilation. Moreover, this was found to be common to both Chinese and Western endeavours.

Yet, although no clear way forward has been found, this is not to say that one cannot, and does not, exist. Such a claim would be to be consumed by the conceit that one perspective can explain all; and that the system could be completed. In this respect, whilst one construction of otherness has been traced in this article, this is by no means the only construction. At least three further lines of enquiry immediately suggest themselves. First, this article must accept criticism insofar as it has been limited to thinking about the self-other relation from one direction only. In other words, what would it mean to see things from the position of 'the other'? More space would be needed to explore this question, but it returns to important themes already raised by this article. In seeing the relationship from only one direction we exclude the experience and perspective of the other, an experience and perspective which might not be framed in terms of the self. This also raises the question as to whether the other sees itself in a relationship with the self at all. We are then thrown back to doubting the possibility of relationality. The second line of enquiry is to construct a more complete picture than what has been drawn here by investigating the notions of otherness (and self) that this article has noted but left in abeyance. If it is the case that 'radical otherness' runs into an aporia, perhaps this aporia can be traversed by back-tracking and trying a different route. The third line would be to try to draw a more diverse picture by including what has been left out of this picture. This would include not only the nuance and difference that is present in both the Chinese and Western traditions, but also the contributions and insights from thoughts, cultures and traditions beyond these foci. We must always be aware that in this discussion of the relation between self and other, there are 'other others' - both in the sense of voices and perspectives which have been left out and in the sense of alternative constructions of otherness itself.

\section{Bibliography}

Acharya, Amitav (2014) 'Global International Relations (IR) and Regional Worlds: A New Agenda for International Studies', International Studies Quarterly, 58:4, 647-659.

Barabantseva, Elena (2009) 'Change vs. Order: Shijie Meets Tianxia in China's Interactions with the World', Alternatives: Global, Local, Political, 34:2, 129-155.

Bohm, David (1980) Wholeness and implicate order (London: Routledge).

Callahan, William A. (2008) 'Chinese Visions of World Order: Post-hegemonic or a New Hegemony?', International Studies Review, 10(4): 749-761.

Chow, Rey (1991) 'Violence in the Other Country: China as Crisis, Spectacle, and Woman' in Third World Women and the Politics of Feminism, Ann Russo, Lourdes Torres and Chandra Talpade Mohanty (eds.) (Bloomington: Indiana University Press), 81-100. 
Lau, D.C. (1996) 'Introduction' in Tao Te Ching (Hong Kong: Chinese University Press, $2^{\text {nd }}$ ed.), ix-xl.

Derrida, Jacques (1993) Aporias: dying-awaiting (one another at) the "limits of truth" (Stanford: Stanford University Press).

Dillon Michael (2000) 'Poststructuralism, complexity and poetics', Theory, Culture \& Society 17(5): 1-26.

Gruffyd Jones, Branwen (2006) Decolonizing International Relations (Lanham: Rowman \& Littlefield).

Hagström, Linus and Astrid H.M. Nordin (2017) 'Are Soft and Hard Power Inevitably Intertwined? The Politics of Harmony in China, the West and Japan', WISC. Taipei.

Hall, David L. and Roger T. Ames (1995) Anticipating China : thinking through the narratives of Chinese and Western culture (Albany: State University of New York Press).

Huang Chiung-Chiu (2015) 'Balance of relationship: the essence of Myanmar's China policy', The Pacific Review 28(2), 189-210.

Huang Chiung-Chiu and Shih Chih-yu. (2014) Harmonious intervention: China's quest for relational security (Farnham: Ashgate).

Inayatullah, Naeem and David L. Blaney (1996) 'Knowing encounters: beyond parochialism in International Relations theory' in Yosef Lapid and Friedrich Kratochwil (eds) The return of culture and identity in IR theory (London: Lynne Rienner Publishers), 6584.

Inayatullah, Naeem and David L. Blaney (2004) International relations and the problem of difference (New York: Routledge).

Jackson, Patrick T. and Daniel Nexon (1999) 'Relations before states: substance, process and the study of world politics', European Journal of International Relations 5(3), 291332.

Kristensen, Peter Marcus and Ras Tind Nielsen (2013) 'Constructing a Chinese international relations theory: A sociological approach to intellectual innovation', International Political Sociology, 7(1), 19-40.

Laozi (1996) Tao Te Ching (Hong Kong: Chinese University Press).

Levinas, Emanuel (1998) Of God who comes to mind (Stanford: Stanford University Press).

Ling, L.H.M. (2014) The Dao of world politics: towards a post-Westphalian, worldist international relations (Abingdon: Routledge).

Nordin, Astrid H.M. (2012) 'Space for the Future: Exhibiting China in the World at the Shanghai Expo', China Information 26(2), 235-249.

Nordin, Astrid H.M. (2016a) China's International Relations and Harmonious World: Time, space and multiplicity in World Politics (Abingdon: Routledge).

Nordin, Astrid H. M. (2016b). 'Futures beyond "the West"? Autoimmunity in China's harmonious world', Review of International Studies, 42(1), 156-177.

Nordin, Astrid H.M. and Graham M. Smith (2018) 'Reintroducing friendship to international relations: relational ontologies from China to the West', International Relations of the Acia Pacific, 18(3), 369-396. 
Pasic, Sujata Chakrabarti (1996) 'Culturing International Realtions theory: a call for extension' in Yosef Lapid and Friedrich Kratochwil (eds) The return of culture and identity in IR theory (London: Lynne Rienner Publishers), 85-104.

Qin Yaqing (2009) 'Guanxi benwei yu guocheng jiangou: jiang Zhongguo linian zhiru guoji guanxi lilun' [Relationality and processual construction: bringing Chinese ideas into international relations theory], Zhongguo shehui kexue, 30(4), 5-20.

Qin Yaqing (2016) 'Relational theory of world politics', International Studies Review, 18(1), $33-47$.

Qin Yaqing (2018) A Relational theory of world politics (Cambridge: Cambridge University Press).

Rojas, Christina (2016) 'Contesting colonial logics of the international: toward a relational politics for the pluriverse', International Political Sociology, 10(4), 369-382.

Roshchin, Evgeny (2018) Friendship among nations (Manchester: Manchester University Press).

Shih Chih-yu (2010) 'The Self That Has No Other: Asia as a Democratic Perspective on Postcolonial Modernity'. Theory vs. Policy? Connecting Scholars and Practitioners, New Orleans.

Shih Chih-yu (2016) 'Affirmative balance of the Singapore-Taiwan relationship: a bilateral perspective on the relational turn in international relations', International Studies Review, 18(4), 681-701.

Smith, Graham M. (2011). Friendship and the political: Kierkegaard, Nietzsche, Schmitt. Exeter, Imprint-academic.

Smith, Graham M. (2011) 'Friendship and the world of states', International Politics, 48(1), 10-27.

Tickner, Arlene B. and David L. Blaney (2012) Thinking International Relations Differently (New York: Routledge).

Wendt, Alexander (1999) Social theory of international politics (Cambridge: Cambridge University Press).

Wikimedia commons (2012) Yin yang.svg. Available at: http://commons.wikimedia.org/wiki/File:Yin_yang.svg.

Wolf, Margery (1994) 'Beyond the patrilineal self: constructing gender in China' in Roger T. Ames, Wimal Dissanayake and Thomas P. Kasulis (eds) Self as person in Asian theory and practice (Albany: State University of New York Press), 251-267.

Zhao Tingyang (2005) Tianxia tixi: shijie zhidu zhexue taolun (Nanjing: Jiangsu jiaoyu chubanshe).

Zhao Tingyang (2006a) Guanyu hexie shijie de sikao [Reflections on harmonious world]. Shijie jingji yu zhengzhi 9, 1.

Zhao Tingyang (2006b) 'Rethinking Empire from a Chinese Concept "All-under-Heaven" (Tianxia)', Social Identities 12(1), 29-41.

Zehfuss, Maja (2001) 'Constructivism and identity: a dangerous liaison', European Journal of International Realtion 7(3), 315-348. 